\title{
Del view al share: el papel de la comunicación viral en la transformación del ecosistema mediático
}

\section{Alberto Dafonte-Gómez ${ }^{1}$ Xabier Martínez-Rolán²}

Recibido: 2015-07-31

Enviado a pares: 2015-07-31
Aprobado por pares: 2015-09-21

Aceptado: 2015-09-26

DOI: 10.5294/pacla.2016.19.2.7

Para citar este artículo / To reference this article / Para citar este artigo

Dafonte-Gómez, A. Martínez-Rolán, X.(Junio de 2016). Del view al share: el papel de la comunicación viral en la transformación del ecosistema mediático. Palabra Clave, 19(2), 501-525. DOI: 10.5294/pacla.2016.19.2.7

\section{Resumen}

Desde la irrupción, a mediados de la década de 1990, del concepto de 'media virus', el fenómeno de la comunicación viral no ha hecho más que expandirse, integrarse y transformar el ecosistema mediático. El presente artículo reflexiona sobre las transformaciones que el auge del comportamiento social de los usuarios ha producido en la forma en que empresas y medios de comunicación crean y distribuyen sus contenidos. Tras un recorrido inicial a través de las principales investigaciones sobre el comportamiento de los usuarios frente a los contenidos mediáticos y a las motivaciones que tienen para compartirlos con su comunidad, establecemos las relaciones entre estas nuevas pautas de consumo y distribución entre pares y las adaptaciones de los contenidos a las prácticas que se vienen operando en la actualidad, a través de un estudio de caso sobre las opciones de compartibilidad en los principales periódicos en línea de Argentina, Brasil, Bolivia, Chile, Colombia, España, Guatemala, México, Perú, Portugal y Venezuela. 


\section{Palabras clave}

Medios de comunicación de masas; comunicación interactiva; interacción social; transferencia de información; difusión de la información (Fuente: Tesauro de la Unesco).

\section{From the View to Share: The Role of Viral Communication in Transforming the Media Ecosystem}

\section{Abstract}

Since the emergence in the mid-1990s, the concept of "media virus", the phenomenon of viral communication has not done more to expand, integrate and transform the media ecosystem. This article reflects on the changes that the rise of social user behavior has occurred in the way media companies create and distribute content. Following an initial tour on the behavior of users against media content and the motivations that they have to share with their community, establish relationships between these new patterns of consumption and distribution among peers and the adjustments to the content to the practices have been occurring at present. Through a case study on shareability options in major online newspapers in Argentina, Brazil, Bolivia, Chile, Colombia, Spain, Guatemala, Mexico, Peru, Portugal and Venezuela.

\section{Keywords}

Mass media; interactive communication; social interaction; information transfer; information dissemination (Source: Unesco Thesaurus). 


\section{Do view ao share: o papel da comunicação viral na transformação do ecossistema midiático}

\section{Resumo}

Desde a irrupção, a meados da década de 1990, do conceito de "media virus", o fenômeno da comunicação viral não tem feito mais do que se expandir, integrar e transformar o ecossistema midiático. Este artigo reflete sobre as transformações que o auge do comportamento social dos usuários vem produzindo na forma em que empresas e meios de comunicação criam e distribuem seus conteúdos. Após um percorrido inicial pelas principais pesquisas sobre o comportamento dos usuários diante dos conteúdos midiáticos e das motivações que têm para compartilhá-los com sua comunidade, estabelecemos as relações entre essas novas normas de consumo e a distribuição entre pares e as adaptações dos conteúdos às práticas que se vêm operando na atualidade por meio de um estudo de caso sobre as opções de compartilhamento nos principais jornais on-line da Argentina, Brasil, Bolívia, Chile, Colômbia, Espanha, Guatemala, México, Peru, Portugal e Venezuela.

\section{Palavras-chave}

Meios de comunicação de massas; comunicação interativa; interação social; transferência de informação; difusão da informação (Fonte: Tesauro da Unesco). 


\section{Introducción. La distribución de contenidos en el ecosistema mediático: de la imprenta a internet}

Dentro del ecosistema conformado por los medios de comunicación, las empresas, las instituciones y los individuos se producen intercambios de elementos de valor entre los distintos actores que funcionan como eslabones en una suerte de cadena trófica bidireccional. Cada uno de los elementos nutre, en cierta medida, a los restantes en un mercado basado en la satisfacción de las necesidades, la supervivencia económica y el mantenimiento del statu quo entre los actores.

Las empresas e instituciones se guían por lógicas de beneficio económico y conservación del poder que dependen en gran medida del favor de los individuos, consumidores o ciudadanos que adquieren sus productos, votan a los gobiernos o se muestran conformes a las políticas desarrolladas (Castells, 2009; Stanton 2007). Los medios de comunicación han venido funcionando tradicionalmente como el nexo entre estos dos actores, proporcionando, por una parte, volúmenes de audiencia y capacidad de influencia en ella a empresas e instituciones a cambio de contraprestaciones económicas o políticas favorables y, por otra parte, contenidos de información, divulgación o entretenimiento a los individuos a cambio de su tiempo y su atención a los mensajes transmitidos por empresas o instituciones de forma manifiesta u oculta. En cierta medida, el esquema planteado supone que los grandes medios de comunicación funcionan en realidad como servicios de relaciones públicas que administran su influencia a cambio de mantener su propia posición en el sistema.

Los medios de comunicación basan su poder en la capacidad para llegar a públicos masivos entre los que distribuir mensajes pagados por empresas e instituciones y también en su habilidad para orientar a la opinión pública — parafraseando a Cohen (1963), determinan "sobre qué pensar" y en muchos casos, incluso, "qué pensar"- en favor de la causa que convenga a los poderes políticos y económicos que los sostienen. Tradicionalmente, las vías de distribución de contenidos —el "canal” a través del cual difundir los "mensajes" en los modelos del proceso comunicativo más clásicos - han estado en manos de los grandes grupos de comunicación, que 
han establecido oligopolios en su sector, con barreras de entrada legales, tecnológicas o económicas que dificultaban el libre acceso a la posibilidad siquiera de congregar grandes audiencias.

Los avances tecnológicos producidos a lo largo de la historia de los medios de comunicación no habían hecho sino reforzar esa situación hegemónica de la empresa de comunicación frente al ciudadano a través de la sofisticación de los medios y del incremento constante de la capacidad de transmisión de contenidos, hasta que esa misma evolución tecnológica puso en manos del usuario la capacidad de equilibrar esa situación.

La aparición de internet marca el punto de inflexión en esta evolución, si bien sería más apropiado referirse a su proceso de democratización que a su nacimiento: el momento en el que la tecnología de acceso es asequible para una proporción elevada de la población y las herramientas de publicación - blogs y wikis en una primera oleada y redes sociales en la segunda - $\tan$ sencillas que consiguen un nivel de uso masivo.

Concretando esta idea, Manovich (2013, pp. 331-334) señala como característica definitoria de la "era de los medios sociales" que todos los sitios web, aplicaciones y funcionalidades que se desarrollan en su seno están concebidos para su integración más que para su funcionamiento por separado, conformando una ecología propia que integra motores de búsqueda, sistemas de recomendación, editores de blogs, canales web, etcétera, junto con tecnologías accesibles para la producción y difusión de contenidos.

Los "nuevos medios" se mueven en un marco definido por Scolari (2008, pp. 78-110) a través de cinco características: la digitalización, la reticularidad de la estructura, la hipertextualidad y multimedialidad de los contenidos y la capacidad de participación de los usuarios (interactividad). Este nuevo escenario comunicativo favorece que las barreras de entrada para generar y distribuir contenido se hayan visto reducidas a su mínima expresión en internet y que las redes sociales se hayan convertido en el mayor canal de distribución de contenido entre usuarios jamás concebido. 
Es cierto que las grandes corporaciones también usan esta red de distribución, pero nunca antes un canal de estas proporciones había estado al alcance de tanta gente, hasta el punto de que las interacciones de los usuarios a través de sus redes sociales pueden llegar a influir en la agenda mediática (Wihbey, 2014, p. 24; Túñez-López, García, Guevara-Castillo, 2011, p. 64). Es el paso del broadcasting a la comunicación "muchos-a-muchos" (Scolari, 2010, p. 24).

\section{El nuevo modelo de distribución de contenidos}

El modelo de distribución de contenidos imperante hasta nuestros días se basa en que un reducido grupo de emisores hace llegar sus contenidos a audiencias masivas a través de canales controlados mayoritariamente por el poder económico o político (licencias para radio y televisión, apoyos financieros necesarios para levantar y sostener un medio de comunicación tradicional, etcétera). En las sociedades económicamente desarrolladas, los receptores pueden acceder a un gran abanico de medios de comunicación - controlados, eso sí, por un puñado de grupos mediáticos - de manera sencilla y de forma gratuita o a un coste reducido, por lo que las audiencias congregadas en torno a ellos son numerosas y la facilidad para transmitirles mensajes, elevada.

El “viejo modelo” se define, en palabras de Díaz-Nosty (2013, p. 117) como aquel en el que emisor proyecta "propuestas mediáticas unidireccionales, dirigidas a las audiencias receptoras, con una escasa capacidad de estas en la realimentación del discurso", con el añadido de establecer el marco de la agenda mediática en función de los intereses del emisor.

El "nuevo modelo" de distribución en línea ha cambiado el eje de coordenadas y, si bien el esquema de transmisión vertical que acabamos de describir sigue plenamente vigente, la horizontalidad de las redes sociales supone ya un importante contrapeso a esta dinámica (Masip et al., 2015). Es lo que Jenkins, Ford y Green (2013) definen como "un modelo híbrido de circulación”, en el que la mezcla de dinámicas top-down y bottom-up determinan qué contenidos son compartidos y distribuidos entre la sociedad. En este cruce de caminos, conviven esquemas verticales de distribución, esquemas 
horizontales (grassroots, peer-to-peer) y esquemas intermedios en los que la participación de "influenciadores" marca la diferencia en cuanto al nivel de distribución de un mensaje. La intervención de líderes de opinión o prescriptores en la transmisión de la información, como filtros o selectores entre los medios de comunicación y la audiencia, no es nueva en absoluto en el campo de la teoría de la comunicación (Lazarsfeld, Berelson y Gaudet, 1944; Katz y Lazarsfeld, 1955; Katz, 1957), pero nunca antes el proceso había sido tan sencillo, $\tan$ horizontal y $\tan$ inmediato en sus efectos, porque el canal está en manos de los usuarios y no de las corporaciones. Capella, Kim y Albarracín (2014) consideran que este proceso de transmisión de la información en dos etapas - exposición directa (primaria) al medio de comunicación y exposición secundaria a la información a través de nodos sociales- es la característica más relevante del nuevo entorno mediático, y señalan en este sentido:

El "alcance" de un elemento informacional en el ecosistema mediático es producto de la unión de su selección por los miembros de la audiencia y la transmisión a otros individuos usando los medios disponibles dentro del abanico de opciones de transmisión (p. 400). ${ }^{3}$

En 1971 Enzensberger afirmaba (1971/1974, p. 30): "La oposición entre productores y consumidores no es inherente a los medios electrónicos; más bien ha de ser afirmada artificialmente mediante unas medidas económicas y administrativas"; obviamente Enzensberger no se refería a internet, pero anticipaba con nitidez un aspecto clave en nuestros días: la potencialidad de cada individuo de llegar a una gran audiencia.

La capacidad de distribución en la red ya no supone un coste que pocos pueden asumir, sino que puede lograrse también como construcción colectiva de los intereses de los usuarios, que deciden con sus acciones individuales lo que merece la pena ser difundido y lo que no (Masip et al., 2015, p. 369; Díaz-Nosty, 2013).

3 'The 'reach' of any informational item in the media environment is a joint product of its selection by members of the audience and its retransmision by the audience to others using whatever means are available within the space of transmission options”. 
No nos referimos a una simple cuestión de abaratamiento de los medios de producción, facilidad de acceso a la tecnología o ausencia de barreras de entrada legislativas para un medio de tipo tradicional en internet. Estamos hablando de un cambio en las audiencias, que ya no solo escuchan a los medios, sino que se relacionan con ellos de una manera mucho más directa y han adoptado hábitos - no totalmente nuevos, desde luego — de transmisión de la información que les resulta relevante entre sus redes de contactos y que han visto exponencialmente aumentada su capacidad de influencia entre sus semejantes.

¿Es esta práctica social protagonizada por los usuarios tan importante dentro del ecosistema mediático? Díaz-Nosty (2013, p. 137) habla de la "economía de la atención", como la consecuencia de ese comportamiento y de la necesidad de los medios de comunicación de desarrollar estrategias que aprovechen esas "nuevas formas de construcción y difusión de la información”, que Campos-Freire (2015, p. 443) relaciona también con otras formulaciones teóricas, como las economías del like, de la participación, de la colaboración o el "capital social virtual". La adaptación a estos nuevos modelos de consumo a través de la distribución y promoción - que son consideradas competencias centrales del negocio de las empresas de medios por autores como Wirtz (2014) — implica hacer accesibles los medios para los receptores a través de una adaptación de los contenidos a los canales en los que ya se encuentra el público: las distintas redes sociales (Rushkoff, 2014).

El cambio de modelo que describimos implica necesariamente adaptaciones significativas por parte de los actores del ecosistema comunicativo, que hasta no hace mucho habían determinado el tipo de relación que los usuarios mantenían con los contenidos: los medios de comunicación. Del mismo modo que la adopción de mecanismos de participación (Masip y Suau, 2014) marcó los primeros cambios de los medios de comunicación en línea fundamentalmente por causas económicas (Vujnovic et al., 2010; Thurman y Hermida. 2010; Masip et al., 2015), serán esas mismas causas las que nos lleven a reflexionar sobre el modo en que un medio de comunicación debe adaptarse a un ecosistema, en el que un volumen muy eleva- 
do de su tráfico proviene de las redes sociales y, más concretamente, de lo que los individuos comparten en sus perfiles en redes sociales (Newman, 2011; Pew Research Center, 2015).

\section{La era del share: ¿por qué compartimos contenidos?}

Los seres humanos compartimos información con nuestros semejantes desde el principio de los tiempos. A una escala global, la transmisión del conocimiento generado a través de la observación y la experiencia es la clave de la evolución científica y social de la humanidad, pero no es necesario fijarse en tan altas metas para observar la importancia de compartir información, ya que forma parte de nuestro comportamiento cotidiano; toda expresión comunicativa tiene como finalidad "compartir algo con la persona a la que se dirige” (Martín-Algarra, 2003, p. 68): constantemente estamos recomendando cosas que hemos probado o transmitiendo aquello que nos han contado; cabe pensar que lo hacemos para ayudar a los demás con nuestra experiencia, pero ¿existen otras motivaciones posibles más allá de la que parece obvia?

Sundaram, Mitra y Webster (1998), Chung y Darke (2006), Ho y Dempsey (2010) o Huang, Chen y Wang (2012) destacan dos aspectos clave en este sentido: por una parte, la necesidad de los individuos de sentirse integrados en comunidades compartiendo información que consideran valiosa para sus semejantes y, por otra, la necesidad de diferenciación de los individuos dentro de esas mismas comunidades a través de la difusión de elecciones de consumo cultural, que proyectan una buena imagen de sí mismos. La cuestión de la integración o validación social en el grupo y la autoexpresión dentro de él son aspectos muy presentes en la investigación sobre motivaciones para compartir información en línea (Capella, Kim y Albarracín, 2014), pero existe otro elemento determinante en la decisión de compartir contenidos: las emociones que transmiten.

Algunas investigaciones, como las de Porter y Golan (2002), Dobele et al., (2007), Berger y Milkman (2010), Eckler y Bolls (2011), Teixeira (2012), Guadagno et al., (2013) o Dafonte-Gómez (2014), coinciden 
en la gran importancia de las emociones que los contenidos suscitan en un usuario para determinar el hecho de que lo comparta o no y, en general, coinciden también en la mayor probabilidad de viralización de aquellos contenidos que transmiten emociones positivas. Probablemente, se deba en gran medida a que, como apuntan Guadagno et al. (2013, p. 2312), "cuando la gente ve clips de vídeo en internet, puede experimentar las mismas emociones de los protagonistas de los vídeos, y al enviar el clip a otros, anticipa que quien lo vea experimentará emociones similares”. ${ }^{4}$

Si bien tanto los aspectos relacionados con la psicología del individuo y su relación con el grupo como aquellos más ligados al contenido de la pieza potencialmente viral tienen una incidencia clara en la toma de decisión, no son el único aspecto que influye en el acto de compartir.

\section{La transmisión viral de la información: la adaptación del contenido al medio}

El papel del individuo como eje central de la transmisión viral de los contenidos es indiscutible. Mientras la perspectiva más clásica del marketing viral describe a los usuarios como meros transmisores de la información (Rushkoff, 1994; Rayport, 1996; Welker, 2002; Wilson, 2012) —incluso de forma involuntaria en sus planteamientos iniciales-, el enfoque actual tiende a contemplar los beneficios de que el usuario manipule el contenido ofrecido por el emisor apropiándose de él y favoreciendo una asunción y distribución menos superficial de los mensajes.

Cuando Jenkins et al. (2008, p. 11) plantean el concepto de spreadable media hacen hincapié en el papel del consumidor no como mero distribuidor ciego de unidades de información, sino como participante activo a través de la apropiación y modificación del contenido. Desde una perspectiva similar, McCracken (2009) habla de multipliers, como aquellos que se apropian de cualquier tipo de producto y sobre él son capaces de construir un proceso cultural en el que el contenido inicial es solo el punto de par-

4 "When people watch Internet video clips, they may experience the same emotions as the people in the clips, and by forwarding that clip, the anticipate that the receiver will experience similar emotions”. 
tida. Godin (2000) o Gladwell (2000) se habían referido también, desde planteamientos más comerciales, al papel clave de ciertos tipos de usuarios - sneezers (subdivididos en promiscuous sneezers y powerful sneezers) en el caso de Godin; connectors, mavens y salesmen, en el caso de Gladwell-, como aquellos con mayor capacidad para viralizar un mensaje, definidos fundamentalmente según su predisposición para transmitir ideas o información novedosa, el tamaño de su red de contactos y la credibilidad que tienen entre ellos. El enfoque de estos autores da una especial relevancia en el proceso de viralización a una élite de usuarios (no muy distintos de los más clásicos líderes de opinión o prescriptores), que tienen una mayor capacidad para hacer que una idea se propague a través de las redes, mientras que el enfoque de Jenkins et al. (2008) o de McCracken (2009) es más horizontal y social.

A pesar de las diversas perspectivas posibles en torno al papel de los usuarios en la transmisión viral de los contenidos, hablamos, en general, de individuos que tienen en sus manos la potencialidad de hacer circular la información entre sus redes de contactos con un nivel de proximidad, credibilidad y autoridad, que un medio de comunicación a través de sus canales habituales no puede igualar. Los prescriptores ya no son solo reconocidos especialistas en una materia concreta avalados por sus trayectoria profesional, son también nuestros círculos de amigos y familiares que comparten con nosotros sus experiencias y pasiones.

Al "activar" la viralidad, los medios de comunicación juegan con ventaja con respecto a los usuarios individuales. Los contenidos de los medios de comunicación llegan a millones de usuarios de un modo simultáneo en el momento en el que se emiten, lo cual supone un importante punto de partida para iniciar la distribución viral de un contenido entre usuarios; es lo que Watts, Peretti y Frumin (2007) denominan big-seed marketing, modelo que combina las virtudes del broadcasting tradicional asegurando una sólida base de receptores del mensaje inicial, con una optimización de los contenidos y de la interfaz para su difusión posterior peer-to-peer.

La investigación sobre la viralidad de la información defiende desde sus inicios la necesidad de que los mensajes que pretenden "inocularse" 
circulen a través de las redes de contactos ya creadas por los usuarios de una forma natural. En este sentido, Rayport (1996) ya señalaba, en uno de los artículos fundacionales del marketing viral: "Deja que los comportamientos del público objetivo transporten el mensaje", ${ }^{5}$ como un aspecto clave del nuevo enfoque viral de distribución de contenidos. En la misma idea, han incidido posteriormente otros investigadores, como Wilson (2012), que sitúa entre los seis elementos de una estrategia viral la utilización de redes de comunicación ya existentes y añade la necesidad de facilitar la transmisión de los virus entre los usuarios. Desde una perspectiva mucho más social y cultural que comercial, Jenkins, Ford y Green (2013, p. 298) también destacan la importancia capital de motivar y favorecer la acción de compatir en los contenidos que se ofrecen a los usuarios.

Godin (2000) ya había incidido también a lo largo de su obra Unleashing the ideavirus en la importancia crucial de dar facilidades a los usuarios para que los virus se expandan, usando como ejemplo, entre otros, el de situar un botón para compartir por correo electrónico un artículo dentro de un sitio web. Si bien el ejemplo de Godin demuestra lo mucho que han cambiado las cosas entre 2000 y 2015, la idea de fondo en cuanto a medios de comunicación se refiere sigue siendo la misma y es persistente: allanar el camino para que la interfaz no suponga un obstáculo cuando un usuario haya tomado la decisión de compartir un contenido.

\section{Estudio de caso: la compartibilidad de las noticias en la prensa iberoamericana}

Tal y como hemos señalado, cabe pensar que las transformaciones descritas en el ecosistema han producido algún tipo de cambio en los medios de comunicación como respuesta adaptativa. Para comprobar esta hipótesis se ha llevado a cabo un estudio de tipo cuantitativo sobre las opciones de compartibilidad de contenidos que ofrecen los periódicos digitales a través de diferentes dispositivos tanto desde un ordenador personal como desde un dispositivo móvil, dado el elevado índice de penetración entre los usua-

5 "Let the behaviors of the target community carry the message". 
rios de teléfonos inteligentes y tabletas (eMarketer, 2014). La compartibilidad o shareability es un término acuñado por Freyd (1983), que se aplica en el entorno virtual a la optimización de las opciones y capacidades que un contenido en red posee para ser compartido; aunque el término puede aplicarse a todos los aspectos formales y de contenido de una pieza de información, hemos optado por limitarnos en este caso al análisis de las opciones de distribución a través de redes sociales, que ofrecen los medios y noticias que conformaron la muestra.

\section{Muestra de estudio}

La muestra de estudio está constituida por los dos principales periódicos digitales de cada uno de los países iberoamericanos más poblados, más España y Portugal. Así, los 11 países que conforman la muestra de estudio son los siguientes: Argentina, Brasil, Bolivia, Chile, Colombia, España, Guatemala, México, Perú, Portugal y Venezuela.

Para seleccionar los dos periódicos digitales más populares en internet, se ha tomado como referencia el ranquin Alexa, compañía de Amazon que ofrece información sobre el número de visitas que recibe un sitio web. Los datos recabados por la compañía permiten establecer un ranquin sobre los sitios web con más tráfico con posibilidad de segmentación geográfica. El ranquin nacional fue la división empleada para identificar los periódicos más consultados, reflejados en la tabla 1 . No se ha tenido en cuenta el hecho de que el medio analizado disponga o no de una versión en papel además de la digital.

La acotación temporal de la muestra se formalizó el 8 de julio de 2015, fecha de consulta de la portada de cada noticiario y de las noticias seleccionadas para su doble observación. A las 14:00 h se accedió por primera vez a las portadas de los diarios digitales y a la noticia más destacada de la portada. Posteriormente, para evaluar su impacto en la red respecto de la compartibilidad se realizó un control de cada noticia una vez transcurridas 100 horas (el 12 de julio a las 18:00 h) desde la primera consulta; tiempo suficiente para evaluar el recorrido viral de un contenido. 


\section{Tabla 1. Muestra de estudio seleccionada}

\begin{tabular}{|c|c|c|c|c|}
\hline País & Periódico & Web & $\begin{array}{c}\text { Alexa } \\
\text { (posición } \\
\text { nacional) }\end{array}$ & Noticia de portada \\
\hline Argentina & La Nación & http://lanacion.com.ar/ & 9 & $\begin{array}{l}\text { Rechazo de empresarios a una medida que juzgan } \\
\text { peligrosa }\end{array}$ \\
\hline Argentina & Clarín & http://clarin.com/ & 10 & $\begin{array}{l}\text { La Corte y los titulares de las Cámaras Federales, } \\
\text { duros con la Ley de Subrogancias de Jueces }\end{array}$ \\
\hline Bolivia & El Deber & http://eldeber.com.bo/ & 16 & Bolivia recibe a Francisco con los brazos abiertos \\
\hline Bolivia & La Razón & http://la-razon.com/ & 20 & $\begin{array}{l}\text { Con la casa lista, Bolivia abre sus brazos al papa } \\
\text { latinoamericano }\end{array}$ \\
\hline Brasil & Globo & http://globo.com/ & 6 & $\begin{array}{l}\text { Grécia entra com pedido formal de empréstimo para } \\
\text { zona do euro }\end{array}$ \\
\hline Brasil & $\begin{array}{l}\text { Folha de São } \\
\text { Paulo }\end{array}$ & http://folha.uol.com.br/ & 22 & $\begin{array}{l}\text { Grécia pede à União Europeia novo resgate financeiro } \\
\text { e promete reformas }\end{array}$ \\
\hline Chile & $\begin{array}{l}\text { El Mercurio } \\
\text { Online }\end{array}$ & http://emol.com/ & 5 & $\begin{array}{l}\text { IPC de junio anota alza de } 0.5 \% \text { y se ubica por sobre } \\
\text { las proyecciones del mercado }\end{array}$ \\
\hline Chile & $\begin{array}{l}\text { Las Últimas } \\
\text { Noticias }\end{array}$ & http://lun.com/ & 7 & 42 wasaps chistosos de mamás chilenas \\
\hline Colombia & El Tiempo & http://eltiempo.com/ & 11 & En el país, cuatro de cada cinco suicidas son hombres \\
\hline Colombia & El Espectador & $\begin{array}{l}\text { http://elespectador. } \\
\text { com/ }\end{array}$ & 19 & $\begin{array}{l}\text { Primera reunión oficial de talibanes y Gobierno } \\
\text { afgano abre camino a la paz }\end{array}$ \\
\hline España & El Mundo & http://elmundo.es/ & 11 & $\begin{array}{l}\text { Grecia pide un préstamo a tres años y ofrece reformas } \\
\text { tributarias inmediatas }\end{array}$ \\
\hline España & El País & http://elpais.com/ & 12 & $\begin{array}{l}\text { Tsipras acepta tres concesiones importantes para } \\
\text { obtener el rescate }\end{array}$ \\
\hline Guatemala & Soy 502 & http://soy502.com/ & 6 & $\begin{array}{l}\text { Terminó el plazo de inscripción de candidatos para } \\
\text { elecciones } 2015\end{array}$ \\
\hline Guatemala & Prensa Libre & http://prensalibre.com/ & 13 & Se reduce inscripción de candidatos \\
\hline México & El Universal & $\begin{array}{l}\text { http://eluniversal.com. } \\
\mathrm{mx} /\end{array}$ & 24 & $\begin{array}{l}\text { Lanzan licitaciones por } 91 \mathrm{mmdp} \text { para nuevo } \\
\text { aeropuerto }\end{array}$ \\
\hline México & Debate & http://debate.com.mx/ & 31 & Policía presta su arma, suben foto al Face y lo arrestan \\
\hline Perú & El Comercio & http://elcomercio.pe/ & 9 & $\begin{array}{l}\text { Examiga de Nadine Heredia la acusa de proteger a } \\
\text { Belaunde }\end{array}$ \\
\hline Perú & La República & http://larepublica.pe/ & 25 & $\begin{array}{l}\text { Heladas y ventarrones castigan pueblos de Puno y } \\
\text { Arequipa }\end{array}$ \\
\hline Portugal & Público & http://publico.pt/ & 18 & $\begin{array}{l}\text { Ao minuto: Grécia pede apoio imediato e entrega } \\
\text { propostas até quinta-feira }\end{array}$ \\
\hline Portugal & $\begin{array}{l}\text { Diario de } \\
\text { Notícias }\end{array}$ & http://dn.pt/ & 24 & $\begin{array}{l}\text { Oficial: bancos gregos não reabrem esta semana. } \\
\text { Tsipras reúne-se com Presidente e líder de partido To } \\
\text { Potami. BCE não dá nem mais um cêntimo }\end{array}$ \\
\hline Venezuela & La Patilla & http://lapatilla.com/ & 7 & El indetenible deterioro de la refinería de Amuay \\
\hline Venezuela & El Nacional & http://el-nacional.com/ & 14 & Hallaron 175000 toneladas de semillas dañadas \\
\hline
\end{tabular}

Fuente: elaboración propia a partir de Alexa a día 8 de julio de 2015. 


\section{Ficha de análisis}

La herramienta de análisis se diseñó para poder evaluar las posibilidades que ofrecen las noticias para ser compartidas, atendiendo a su posición en el periódico y al dispositivo de acceso. Esta ficha está estructurada en dos partes diferenciadas; mientras la primera mitad evalúa las opciones que se ofrecen en la portada para compartir el contenido, la segunda evalúa las mismas opciones en el desarrollo de la noticia. Como cada noticia posee una URL única y diferenciada, es posible evaluar el número de veces que una noticia fue compartida en cada plataforma social (tabla 2).

\section{Tabla 2. Herramienta de análisis empleada}

\begin{tabular}{|c|c|}
\hline Noticias de portada & ¿Se puede compartir desde la portada? \\
\hline Versión escritorio & ¿A través de qué redes se puede compartir desde la portada? Facebook, Twitter, Google+ o \\
Pinterest
\end{tabular}

Fuente: elaboración propia.

\section{Resultados}

El análisis de los veintidós periódicos seleccionados ha arrojado interesantes resultados sobre cómo se integran los sitios web de noticias con las plataformas de gestión de redes sociales que propagan sus contenidos.

La posibilidad de poder compartir la propia noticia desde su titular en portada es una opción que aparece en un tercio de la muestra; en todos los casos periódicos latinoamericanos: Soy 502 (Guatemala), Las Últimas Noticias 
(Chile), La Nación (Argentina), El Espectador (Colombia), ElDebate (México), El Comercio y La República (Perú). Cuando es posible compartir el contenido desde la portada, Facebook y Twitter son las redes escogidas. Google+ aparece con menor intensidad y en tan solo un caso (El Comercio, Perú) se registró la posibilidad de compartir una noticia en portada a la red social Pinterest. Desde el interior de la propia noticia es posible compartir no solo en un mayor número de periódicos, sino en un abanico mayor de redes sociales (figuras 1 y 2 ).

Figura 1. Desde dónde se puede compartir la noticia

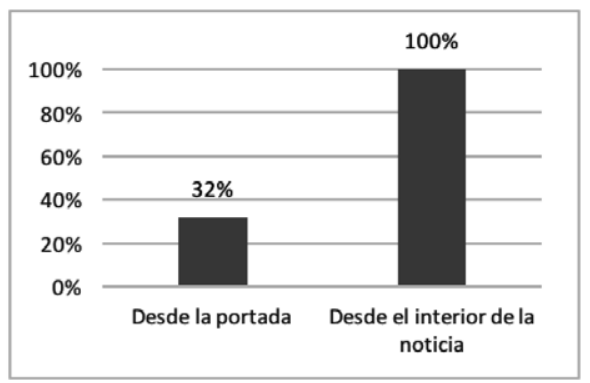

Figura 2. Principales redes empleadas para difundir contenidos desde el interior de la noticia

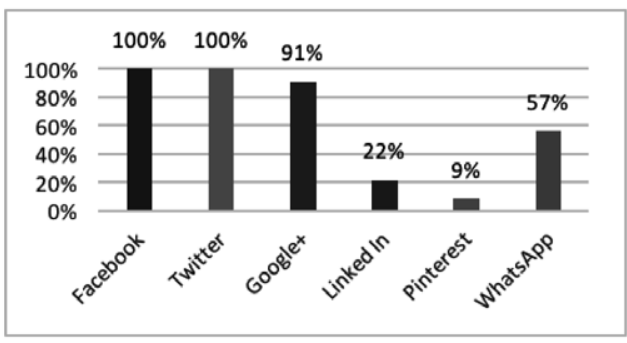

Fuente: elaboración propia.

Facebook, Twitter, Google+, LinkedIn, Pinterest y WhatsApp (esta última solo en la versión móvil) son las herramientas más empleadas para dar difusión a la noticia una vez leída. De nuevo, Facebook y Twitter son opciones presentes en todos los periódicos, y Google+ aparece disponible en toda la muestra, salvo en Las Últimas Noticias (Chile) y El Nacional (Venezuela). La opción de distribuir contenido en LinkedIn aparece en cinco periódicos (22\% de la muestra) y en Pinterest en tan solo dos periódicos (9\%).

En la versión móvil, se ha detectado cierta adaptación a la fuerte implementación de plataformas de mensajería instantánea; hasta 13 periódicos permiten compartir sus contenidos a través de WhatsApp: los dos periódicos españoles, argentinos, colombianos, mexicanos, brasileños y peruanos, así como en un periódico (El Mercurio Online) chileno.

Por otra parte, es posible comparar y definir cuáles son las redes que generan una mayor viralidad: Facebook y Twitter son las redes sobre las que más se propaga el contenido de los periódicos (tabla 3 ). 


\section{Tabla 3. Volumen de socialización de las noticias analizadas en cada red social (número de veces compartidas en cada red social)}

\begin{tabular}{|c|c|c|c|c|c|c|}
\hline País & Periódico & Facebook & Twitter & Google+ & LinkedIn & Pinterest \\
\hline Guatemala & Soy 502 & 306000 & 0 & 0 & No & No \\
\hline Portugal & Diário de Noticias & 17906 & 33 & 0 & 5 & No \\
\hline Perú & La República & 4619 & 65 & 7 & No & No \\
\hline España & El País & 4441 & 830 & 30 & 11 & No \\
\hline Venezuela & El Nacional & 2252 & 2012 & No & No & No \\
\hline España & El Mundo & 1261 & 299 & 5 & No & No \\
\hline Argentina & La Nación & 1046 & 134 & 0 & - & No \\
\hline Venezuela & La Patilla & 864 & 1052 & 1 & No & No \\
\hline Perú & El Comercio & 428 & 90 & 10 & 0 & 1 \\
\hline Portugal & Publico & 247 & 0 & 0 & 1 & No \\
\hline Chile & El Mercurio Online & 92 & 79 & 0 & No & No \\
\hline México & El Universal & 84 & 228 & 0 & No & No \\
\hline Colombia & El Tiempo & 82 & 41 & 0 & No & No \\
\hline Argentina & Clarín & 80 & 41 & 0 & No & No \\
\hline Bolivia & La Razón & 35 & 8 & 0 & No & No \\
\hline Colombia & El Espectador & 28 & 32 & 0 & No & No \\
\hline Guatemala & Prensa Libre & - & - & 0 & No & No \\
\hline Chile & Las Últimas Noticias & - & - & No & No & No \\
\hline Bolivia & El Deber & - & 12 & 0 & No & No \\
\hline México & El Debate & - & - & 0 & No & No \\
\hline Brasil & Globo & - & - & 0 & No & - \\
\hline Brasil & Folha de São Paulo & - & - & 0 & - & No \\
\hline
\end{tabular}

Fuente: elaboración propia.

Se trata, en muchos casos, de contenidos compartidos miles de veces, sobre todo en Facebook, que se sitúa por encima de Twitter como red de propagación más efectiva (salvo en los casos de La Patilla, El Universal y El Espectador).

Google + y LinkedIn, a mucha distancia de las dos redes anteriores, se posicionan como herramientas de escasa utilización para difundir las noticias de los periódicos. 
Las posibilidades de compartir son fundamentales. En Facebook los contenidos pueden compartirse mediante una publicación ( $81 \%$ de los periódicos) o a través del característico "like" (41\%), aunque la publicación es la fórmula más empleada.

Esa dualidad a la hora de redifundir la información se repite en Google+, aunque ninguna de las dos fórmulas — publicación o “+1"- destaca sobre la otra.

El caso de Twitter es más peculiar, porque, aunque solo existe una única manera de publicar el contenido (el microblogging), la estructura del tuiteo no siempre es la misma (figura 3).

Figura 3. Estructura del tuit compartido

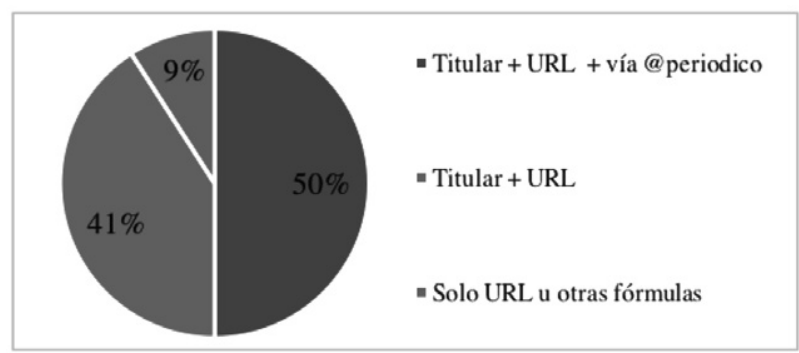

Fuente: elaboración propia.

Solo la mitad de la muestra emplea una estructura que referencia al periódico que la ha publicado; la otra mitad de la muestra incluye el enlace, pero no siempre el titular, lo cual redunda en peores registros en lo que respecta a número de veces compartidas.

Compartir contenido en línea necesita no solo proveer las posibilidades necesarias, sino también cuidar de los aspectos relativos a la usabilidad y experiencia de usuario. En este sentido, la ubicación de los botones que permiten socializar el contenido resulta de especial relevancia, destacando en la pantalla tres posiciones principales para su ubicación (arriba, junto al titular; abajo, al finalizar la noticia; o en lateral, derecho o izquierdo, generalmente con posición estática), sin perjuicio de otro tipo de posiciones minoritarias (pop-up, footer o header) (figura 4). 
Figura 4. Posición de los botones para compartir el contenido

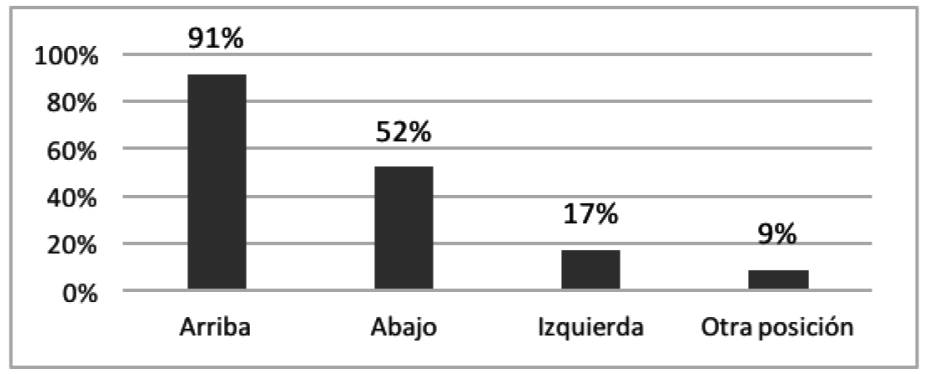

Fuente: elaboración propia.

En este sentido, todos los periódicos de los botones en alguna de las tres posiciones principales. De hecho, a excepción de El Universal (México), todos poseen los botones en la posición superior y $60 \%$ de ellos refuerza la posibilidad de compartir contenidos ubicando nuevamente en la parte inferior o lateral los botones.

También se ha observado que los periódicos que ubican los botones de compartir en una sola posición muestran niveles de difusión inferiores a los diarios que incluyen dichos botones en, al menos, dos posiciones.

Otra opción que los periódicos proveen para el acceso a contenido viralizado o viralizable son los diferentes ránquines que implementan en el lateral de la web (bien en la página de inicio, bien en el desarrollo de la noticia), y que aparecen en dos tercios de la muestra analizada: $55 \%$ de los medios estudiados dispone de ranquin de noticias más leídas, mientras que solo $23 \%$ presenta el ranquin de noticias más compartidas.

\section{Conclusiones}

El artículo desarrollado ha permitido perfilar la adaptación de los principales periódicos en línea iberoamericanos a los cambios que las prácticas sociales de los usuarios han introducido en el ecosistema comunicativo, a través de la evaluación de la compartibilidad de sus contenidos en las diferentes redes sociales. 
Hemos constatado que existe una correlación directa entre las redes sociales con mayor número de usuarios y tráfico — Facebook y Twittery las posibilidades que la prensa brinda para compartir contenidos a través de ellas. El número de veces que los contenidos han sido compartidos permite bosquejar una radiografía de la situación de las redes sociales en América Latina prácticamente monocromática, con una posición preeminente de Facebook seguido de cerca por Twitter, a gran distancia de otras opciones estudiadas. En este sentido, cabe destacar la sobrerrepresentación de Google+, red muy integrada en los periódicos, pero residual en cuanto a capacidad de distribución de contenido.

Compartir el contenido desde el propio titular de portada es una interesante tendencia en el periodismo digital, aunque la investigación llevada a cabo no permite establecer una correlación directa con una mayor propagación viral de la noticia; salvo en Soy 502, ningún otro periódico que incluye la posibilidad de compartir contenido desde la portada ofrece cifras de compartibilidad superiores a la media.

Se ha constatado, por otra parte, el esfuerzo que algunos periódicos están realizando para adaptarse al consumo móvil, al incluir, en esta versión de navegación, la posibilidad de compartir contenido a través de WhatsApp.

Además de las herramientas para compartir contenido, algunos periódicos comienzan a prestar atención a criterios de usabilidad web, entre los que destaca la ubicación de complementos sociales en la pantalla, y, en menor medida, la puesta en valor de la información recuperada de sus usuarios, como la implementación de ránquines de noticias más leídas, populares o compartidas.

Diez años después del aterrizaje de las redes sociales, los medios continúan en un proceso de apropiación de sus herramientas, adaptándose a las tendencias y plataformas más usadas, sin llegar en ningún momento a abanderar el cambio o a liderar la web social como productores de contenidos. 


\section{Referencias}

Berger, J.y Milkman, K. (2010). Social transmission, emotion, and the virality of online content. Wharton Research Paper, 10-114. Recuperado el 17 de enero de 2015 de http: / /robingandhi.com/wp-content/ uploads/2011/11/Social-Transmission-Emotion-and-the-Virality-of-Online-Content-Wharton.pdf

Campos-Freire, F. (2015). Adaptación de los medios tradicionales a la innovación de los metamedios. El Profesional de la Información, 24(4), 441-450.

Cappella, J. N., Kim, H. S. y Albarracín, D. (2014). Selection and transmission processes for information in the emerging media environment: psychological motives and message characteristics. Media Psychology, 18(3), 1-29.

Castells, M. (2009). Comunicación y poder. Madrid: Alianza Editorial.

Chung, C. M.y Darke, P. R. (2006). The consumer as advocate: self-relevance, culture, and word-of-mouth. Marketing Letters, 17(4), 269-279.

Cohen, B. C. (1963). The press and foreign policy. Princeton: Princeton University Press.

Dafonte-Gómez, A. (2014). Claves de la publicidad viral: de la motivación a la emoción en los vídeos más compartidos. Comunicar: Revista Científica de Comunicación y Educación, 22(43), 199-207.

Díaz-Nosty, B. (2013). La prensa en el nuevo ecosistema informativo. ¡ Que paren las rotativas! Barcelona: Ariel/Fundación Telefónica.

Dobele, A., Lindgreen, A., Beverland, M., Vanhamme, J. y Van Wijk, R. (2007). Why pass on viral messages? Because they connect emotionally. Business Horizons, 50(4), 291-304. 
Eckler, P. y Bolls, P. (2011). Spreading the virus: Emotional tone of viral advertising and its effect on forwarding intentions and attitudes. Journal of Interactive Advertising, 11(2), 1-11.

eMarketer (2014, 16 de enero). Smartphone users worldwide will total 1.75 billion in 2014. Recuperado el 17 de enero de 2015 de http://goo. $\mathrm{gl} / 8 \mathrm{PL} 64 \mathrm{r}$

Enzensberger, H. M. (1971/1974). Elementos para una teoría de los medios de comunicación. Barcelona: Anagrama.

Freyd, J. J. (1983). Shareability: The social psychology of epistemology. Cognitive Science, 7(3), 191-210.

Gladwell. M. (2000). The tipping point. Nueva York: Little Brown.

Godin, S. (2000). Unleashing the ideavirus. Recuperado el 20 de enero de 2015 de http://sethgodin.typepad.com/seths_blog/files/ 2000Ideavirus.pdf

Guadagno, R. E., Rempala, D. M., Murphy, S. y Okdie, B. M. (2013). What makes a video go viral? An analysis of emotional contagion and Internet memes. Computers in Human Behavior, 29(6), 2312-2319.

Ho, J. Y. y Dempsey, M. (2010). Viral marketing: Motivations to forward online content. Journal of Business Research, 63(9), 1000-1006.

Huang, J., Chen, R. y Wang, X. (2012). Factors influencing intention to forward short Internet videos. Social Behavior and Personality: An International Journal, 40(1), 5-14.

Jenkins, J., Li, X., Kruskopf, D. y Green, J. (2008). If it doesn't spread, it's dead. Creating value in a spreadable marketplace. Recuperado el 20 de enero de 2015 de http:/ / convergenceculture.org/research/ Spreadability_doublesidedprint_final_063009.pdf 
Jenkins, J., Ford, H. y Green, J. (2013). Spreadable media. Creating value and meaning in a networked culture. Nueva York: New York University Press.

Katz,E. (1957). The two-step flow of communication: an up-to-date report on an hypothesis. Public Opinion Quarterly, 21(1), 61-78.

Katz, E. y Lazarsfeld, P. (1955). Personal influence. Nueva York: The Free Press.

Lazarsfeld, P., Berelson, B. y Gaudet, H. (1944). The people's choice: How the voter makes up his mind in a presidential campaign. Nueva York: Columbia University Press

Manovich, L. (2013). Software takes command. Nueva York: Bloomsbury. Recuperado el 22 de febrero de 2015 de http://issuu.com/bloomsburypublishing/docs/9781623566722_web

McCracken, G. (2009). "Consumers" or "Multipliers"? Recuperado el 22 de febrero de 2015 de http:/ / convergenceculture.org/htmlnewsletter/weeklyupdate_20090402.html

Martín-Algarra, M. (2003). Teoría de la comunicación: una propuesta. Madrid: Tecnos.

Masip, P., Guallar, J., Suau, J., Ruiz-Caballero, C. y Peralta, M. (2015). News and social networks: Audiencia behavior. El Profesional de la Información, 24(4), 364-370.

Masip, P. y Suau, J. (2014). Audiencias activas y modelos de participación en los medios de comunicación españoles. Hipertext.net, 12. Recuperado el 25 de febrero de 2015 de http://www.researchgate. net/profile/Pere_Masip/publication/263088537_Audiencias activas_y_modelos_de_participacin_en_los_medios_de_comunicacin_espaoles/links/0a85e539d7c810288f000000.pdf

Newman, N. (2011). Mainstream media and the distribution of news in the age of social discovery. Reuters Institute for the Study of Journalism, University of Oxford. 
Pew Research Center (2015). The evolving role of news on Twitter and Facebook. Recuperado el 25 de febrero de 2015 de http: / / www.journalism. org/files/2015/07/Twitter-and-News-Survey-Report-FINAL2.pdf

Porter, L.y Golan, G. J. (2006). From subservient chickens to brawny men: a comparison of viral advertising to television advertising. Journal of Interactive Advertising, 6(2), 30-38.

Rayport, J. (1996). The virus of marketing. Recuperado el 3 de marzo de 2015 de http://www.fastcompany.com/27701/virus-marketing

Rushkoff, D. (1994). Media virus. Nueva York: Ballantine.

Rushkoff, D. (2014). On the economy of likes. Recuperado el 3 de marzo de 2015 de http:/ / www.rushkoff.com/storage/Rhapsody\%20magazine\%20_\%20Apr\%202014\%20\%20Ink\%20eMagazines.pdf

Scolari, C. A. (2008). Hipermediaciones: elementos para una teoría de la comunicación digital interactiva. Barcelona: Gedisa.

Scolari, C. (2010). Ecología de los medios: mapa de un nicho teórico. Quaderns del CAC, 34(13), 17-25.

Stanton, R. C. (2007). All news is local: The failure of the media to reflect world events in a globalized age. Jefferson, NC: McFarland \& Company.

Sundaram, D. S., Mitra, K. y Webster, C. (1998). Word-of-mouth communications: A motivational analysis. Advances in Consumer Research, 25(1), 527-531.

Teixeira, T. (2012). The new science of viral ads. Harvard Business Review, $90(3), 25-27$.

Thurman, N. y Hermida, A. (2010). Gotcha: How newsroom norms are shaping participatory journalism online. En S. Tunney y G. Mo- 
naghan (eds.), Web journalism: a new form of citizenship? (pp. 4662). Eastbourne, UK: Sussex Academic Press. Recuperado el 3 de marzo de 2015 de http: / /openaccess.city.ac.uk/179/2/thurman hermida_gotcha.pdf

Túñez-López, M., García, J. S. y Guevara-Castillo, M. (2011). Redes sociales y marketing viral: repercusión e incidencia en la construcción de la agenda mediática. Palabra Clave, 14(1), 53-66.

Vujnovic, M., Singer, J. B., Paulussen, S., Heinonen, A., Reich, Z., Quandt, T., ... y Domingo, D. (2010). Exploring the political-economic factors of participatory journalism: Views of online journalists in 10 countries. Journalism Practice, 4(3), 285-296.

Watts, D. J., Peretti, J. y Frumin, M. (2007). Viral marketing for the real world. Harvard Business School Pub. Recuperado el 23 de marzo de 2015 de http://thethingis.typepad.com/Viral_Marketing_for_the_ Real_World.pdf

Welker, C. B. (2002). The paradigm of viral communication. Information Services \& Use, 22(1), 3-8.

Wihbey, J. (2014). The challenges of democratizing news and information: examining data on social media, viral patterns and digital influence. Recuperado el 23 de marzo de 2015 de http://papers.ssrn.com/ sol3/papers.cfm?abstract_id $=2466058$

Wilson, R. F. (2012). The six principles of viral marketing. Recuperado el 24 de marzo de 2015 de http:/ / webmarketingtoday.com/articles/ viral-principles/

Wirtz, B. W. (2014). Business models, value chains and competencies in media markets: a service system perspective. Palabra Clave, 17(4), 1041-1065. 